Georgia State University

ScholarWorks @ Georgia State University

$10-6-2016$

\title{
Framing the Local Context and Estimating the Health Impact of CPPW Obesity Prevention Strategies in Los Angeles County
}

Tony Kuo

Brenda Robles

Justin G. Trogdon

Rachel Ferencik

Follow this and additional works at: https://scholarworks.gsu.edu/ghpc_articles

\section{Recommended Citation}

Kuo, Tony; Robles, Brenda; Trogdon, Justin G.; and Ferencik, Rachel, "Framing the Local Context and Estimating the Health Impact of CPPW Obesity Prevention Strategies in Los Angeles County" (2016). GHPC Articles. 68.

https://scholarworks.gsu.edu/ghpc_articles/68

This Article is brought to you for free and open access by the Georgia Health Policy Center at ScholarWorks @ Georgia State University. It has been accepted for inclusion in GHPC Articles by an authorized administrator of ScholarWorks @ Georgia State University. For more information, please contact scholarworks@gsu.edu. 


\title{
Framing the Local Context and Estimating the Health Impact of CPPW Obesity Prevention Strategies in Los Angeles County, 2010-2012
}

\author{
Tony Kuo, MD, MSHS; Brenda Robles, MPH; Justin G. Trogdon, PhD; Rachel Ferencik, MPA; \\ Paul A. Simon, MD, MPH; Jonathan E. Fielding, MD, MPH
}

Context: Few studies have described the range and health impacts of obesity prevention strategies in local communities supported by the Communities Putting Prevention to Work program. Objective: To address this gap, we reviewed implemented strategies in Los Angeles County (LAC) for 3 program focus areas: physical activity-promotion, health marketing, and creation of healthy food environments. Local context and results from an impact simulation are presented.

Design: Information on population reach and program milestones was synthesized to describe historical and programmatic progress of the obesity prevention efforts during 2010-2012. To forecast health impacts, the Prevention Impacts Simulation Model (PRISM) was used to simulate population health outcomes, including projected changes in obesity burden and health behaviors 30 years into the future. Setting: LAC with more than 9.8 million residents. Participants: Low-income adults and youth who were the intended audiences of the Communities Putting Prevention to Work program in LAC. Intervention: Implemented strategies for the 3 focus areas. Main Outcome Measures: Documentation of program reach and PRISM forecasting of obesity rates and health impacts. Results: Implemented strategies in LAC ranged from best practices in healthy food procurement (estimated reach: 600000 students, 300000 meals per day) to completed shared-use agreements (10+ agreements across 5 school districts) to a series of strategically designed health marketing campaigns on healthy eating (>515 million impressions). On the basis of PRISM simulations, these highlighted program activities have the potential to reduce by 2040 the number of youth
$(-29870)$ and adults $(-94136)$ with obesity, youth

$(-112453)$ and adults $(-855855)$ below recommended levels of physical activity, and youth (-14544) and adults (-28 835) who consumed excess junk food, as compared with baseline (2010-2011). Conclusions: Program context and PRISM-simulated health impacts showed modest but promising results in LAC, which may lead to further population health

\begin{abstract}
Author Affiliations: Division of Chronic Disease and Injury Prevention, Los Angeles County Department of Public Health, Los Angeles, California (Drs Kuo and Simon and Ms Robles); Departments of Family Medicine (Dr Kuo) and Pediatrics (Dr Fielding), David Geffen School of Medicine at the University of California, Los Angeles; Departments of Epidemiology (Drs Kuo and Simon) and Health Policy and Management (Dr Fielding), University of California, Los Angeles Fielding School of Public Health; Department of Health Policy and Management, Gillings School of Global Public Health, University of North Carolina at Chapel Hill (Dr Trogdon); and Georgia Health Policy Center, Georgia State University, Atlanta (Ms Ferencik).

The project in Los Angeles County was supported in part by a cooperative agreement from the Centers for Disease Control and Prevention (CDC) (award \#3U58DP002485-01S1). Technical assistance and the use of the Prevention Impacts Simulation Model were made possible by RTI International and the Georgia Health Policy Center through their CDC contract \#200-2010-F-34677. The authors thank RENEW staff and evaluators from the Division of Chronic Disease and Injury Prevention in the Los Angeles County Department of Public Health for their technical support and contributions to the context scan on policy, systems, and environmental change strategies in Los Angeles County-the scan took place from October to November 2011.
\end{abstract}

The findings and conclusions in this article are those of the authors and do not necessarily represent the views or position of the Los Angeles County Department of Public Health, CDC, University of North Carolina at Chapel Hill, RTI International, or the Georgia Health Policy Center. In accordance with US law, no federal funds provided by the CDC were permitted to be used by community grantees for lobbying or to influence, directly or indirectly, specific pieces of pending or proposed legislation at the federal, state, or local levels. All authors have read and approved the final version.

The authors reported no conflicts of interest and have no financial disclosures.

Correspondence: Tony Kuo, MD, MSHS, Division of Chronic Disease and Injury Prevention, Los Angeles County Department of Public Health, 3530 Wilshire Blvd, 8th Floor, Los Angeles, CA 90010 (tkuo@ph.lacounty.gov).

DOI: $10.1097 / \mathrm{PHH} .0000000000000334$ 
improvements in the future. Downstream health and behavioral surveillance data are needed to confirm these estimates.

KEY WORDS: health impact forecasting, obesity prevention, program evaluation, system dynamics modeling

To address complex community factors that contribute to the obesity epidemic, federal, state, and local agencies in the United States have made substantive investments in community programs that seek to address the physical and social determinants of health (eg, improving the food and physical environments). ${ }^{1-9}$ As a result of these investments, an array of evidence-based and practice-tested strategies (ie, system and structural modifications) has been disseminated across a number of communities in the United States. ${ }^{3}$ In Los Angeles County, these community programs or strategy interventions have included the following: $(a)$ modifying food services and vending practices at food venues operated by county governments, cities, and school districts (eg, incorporating healthy nutrition standards through the contracting process with food vendors or suppliers $)^{10-12} ;(b)$ adapting corner stores or other stores in low-income neighborhoods to offer more fresh produce, including affordable fruit and vegetables; (c) promoting breast-feeding at local hospitals prior to discharge and breast-feeding accommodations in the workplace (eg, access to lactation rooms); $(d)$ increasing access to physical activity opportunities through shared-use agreements (the agreements represent contractually binding documents that enumerate how and where school property and programming are shared between schools and community-based entities) or school district efforts that improve the quality of physical education instruction ${ }^{13,14}$; (e) encouraging active living through land use and transportation planning and other built environment improvements ${ }^{6,15}$; and $(f)$ utilizing health marketing to educate and empower the public to change adverse health behaviors such as excess sugar-sweetened beverage consumption. ${ }^{16,17}$

As in other communities, increasing the likelihood of community acceptance of system or structural modifications to the food and the built environment in Los Angeles County requires ongoing learning about the challenges and impacts of multisector programming and multilevel planning. ${ }^{3,18}$ Although a recent US study has demonstrated the utility and impact of 6 intervention clusters as they relate to downstream cardiovascular health outcomes and risk factor-attributable costs in $2040,{ }^{19}$ this national analysis, from a planning perspective, lacks immediate generalizability to local jurisdictions. Similar enumeration of health impacts in communities that received investments from the Com- munities Putting Prevention to Work (CPPW) program, for example, would provide the supplemental context needed for advancing local decision making about prevention and health protection. ${ }^{20}$ In this regard, Los Angeles County serves as a suitable case study, as the jurisdiction was among the largest of the CPPW program grantees and is home to more than 9.8 million adults and children. ${ }^{21,22}$

Capitalizing on the rich program data available from the Centers for Disease Control and Prevention (CDC) CPPW effort, the present study contributes to closing of the identified gap in public health practice by reviewing the strategies implemented for 3 program focus areas in Los Angeles County: physical activitypromotion, health marketing, and creation of healthy food environments during 2010-2012. Where feasible, the countywide health impacts of these obesity prevention strategies were estimated using the Prevention Impacts Simulation Model (PRISM). ${ }^{19,23,24}$

\section{Methods}

\section{Framing the local context: Synthesis of data about Los Angeles County's obesity prevention strategies during CPPW, 2010-2012}

From October to November 2011, a systematic assessment of institutional policies, systems-level changes, and environmental interventions (a policy/systems/environmental context scan, Figure 1) that were attributable to the local CPPW obesity prevention program in Los Angeles County (called "RENEW") was conducted. Evaluators from the Los Angeles County Department of Public Health spearheaded this assessment and utilized a multistage approach to document and monitor CPPW strategies that were in progress. ${ }^{25}$ During the initial stage of this policy/systems/environmental context scan, evaluators identified and aligned the scan's objectives with key RENEW priorities, developing specific criteria to screen and select program activities for review. Strategy activities were selected and reviewed if they (1) took place in communities with high adult and child obesity prevalence; (2) had CPPW funding in support of the effort(s); and (3) focused on school-based, city-level, food environment, and/or built environment interventions that promoted healthy eating and active living.

Concurrently, during this stage, evaluators identified and interviewed a number of key RENEW program analysts or managers of the various community strategies. Two types of key informants were interviewed: (1) policy analysts who directly managed the selected RENEW efforts; and (2) communications manager(s) who was/were responsible for dissemination 
FIGURE 1 Stages of the CPPW Policy/Systems/Environmental Context Scan in Los Angeles County, 2010-2012

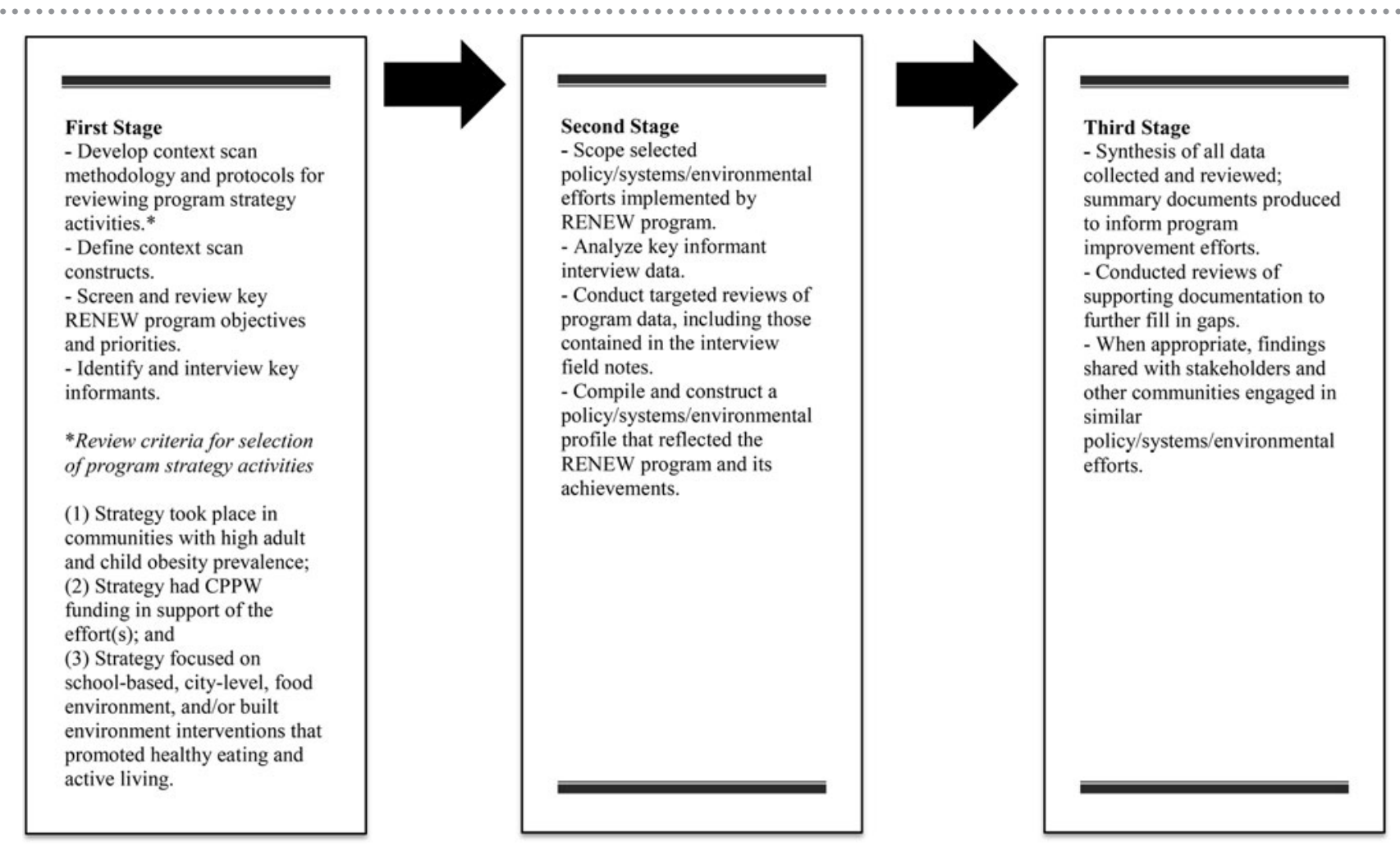

Abbreviation: CPPW, Communities Putting Prevention to Work.

of print and other health marketing materials in support of these efforts.

In total, 7 policy analysts and 1 communications manager were interviewed. A short interactive script containing 3 open-ended questions, each having 1 to 2 follow-up questions or probes, was used to conduct the interviews. The interview questions generally focused on process dimensions and milestones such as (1) activity or policy/systems/environmental accomplishments attributable to RENEW; and (2) identified barriers to or facilitators of these change efforts. Interviews, by phone or in person, averaged 60 minutes. Detailed notes were hand recorded at the time of the interviews. Although audiotaping was available, most interviewees declined to be audiotaped. To augment the interviews, evaluators also obtained paper or electronic documentation to verify and provide context to the various RENEW strategy-related activities (eg, event announcements, written institutional policies or resolutions, health marketing campaign materials).

In the second stage of the assessment, evaluators scoped the selected policy/systems/environmental efforts implemented by RENEW. They reviewed and analyzed the information/qualitative data collected from the key informant interviews, employing thematic analysis procedures. ${ }^{26}$ Data from these semistructured or in-depth interviews were analyzed by 2 evaluators, with a third evaluator serving as the referee if consensus on particular themes or data interpretation could not be reached. First, each evaluator conducted an independent content analysis of the interview field notes to develop themes or describe a policy/systems/environmental profile that reflected the RENEW program. Then, the 2 evaluators compared their notes to develop a consolidated list of themes and generate a qualitative scope for the CPPW strategies that were implemented in the field.

In the third stage, evaluators organized and synthesized the data collected, summarizing them in a spreadsheet by categories: city, assigned RENEW staff in charge of the effort, relevant subcontractors or partners, program objective number (corresponding to the RENEW Community Action Plan), policy/systems/environmental activity details, and policy/systems/environmental change status. All supporting documents provided by interview participants were reviewed in detail to help fill in information gaps. All policy/systems/environmental context scan protocols and materials were reviewed and approved by the Los Angeles County Department of Public Health institutional review board prior to field implementation. 


\section{Forecasting health impact}

To forecast the health impacts of the obesity prevention strategies in the 3 program focus areas (physical activity-promotion, health marketing, and creation of healthy food environments), PRISM was used. This modeling tool simulates health outcomes, including projected changes in obesity burden (proxy indicator for cardiovascular health risk) and health behaviors 30 years into the future. ${ }^{27}$ These simulated outcomes included changes in obesity prevalence, fraction of youth and adults without the recommended levels of physical activity, and fraction of youth and adults who consumed excess junk food (eg, high calorie foods, soda or beverages high in sugar content). Further downstream cardiovascular health outcomes can be modeled, including acute myocardial infarction events, number of hypertension cases, and mortality rates; however, these were not the focus of this analysis. To set baseline values for PRISM policy levers (data profiles) for the model, evaluators from the Los Angeles County Department of Public Health provided analysts at the Georgia Health Policy Center with estimated population reach numbers of the cluster of policy/systems/environmental interventions implemented in Los Angeles County, based on local approximations of population characteristics for the period 2010-2012.

\section{PRISM}

PRISM is a CDC-supported Web-based system dynamics model built to help public health professionals understand and communicate how policies or systemslevel changes in communities can be implemented to reduce and prevent cardiovascular disease (CVD) and other CVD risk factor-related mortality and costs (if data are available) (see screenshot in Figure 2). ${ }^{23,27-29}$ The version of PRISM used in this study simulates the potential impact of implementing various combinations of up to 34 strategy interventions on the occurrence and burden of CVD from the present through 2040. All interventions in the model are based on peer-reviewed literature and discussions with experts working in the field who helped specify and quantify their associative or causal effects.

PRISM has been calibrated to represent US averages by age and gender, for example, obesity prevalence rates from the National Health and Nutrition Examination Survey for 1988-1994 to 1999-2004. For CPPW communities, PRISM was further calibrated for 6

FIGURE 2 Sample Screenshot of the Web-Based PRISM Tool

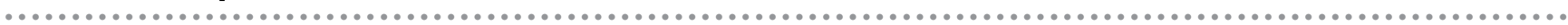
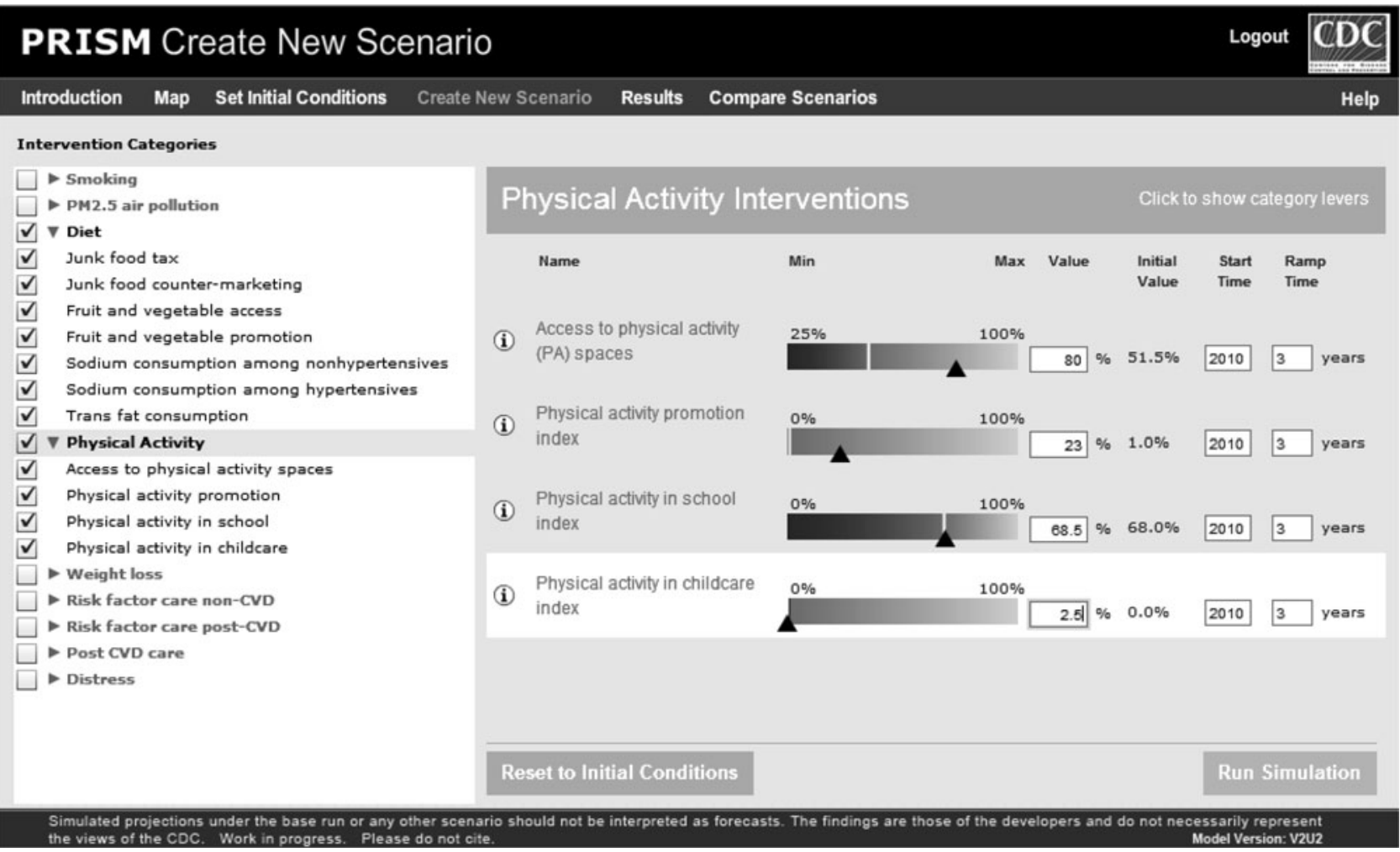

Abbreviation: PRISM, Prevention Impacts Simulation Model. 
distinct community profiles to increase its sensitivity to characteristics not otherwise included in the original model, such as race, ethnicity, and poverty. Where appropriate, sensitivity ranges for the model estimates were generated as a feature of the PRISM analysis. ${ }^{29}$

In the present analysis, 3 public health/health behavior indicators were examined: (1) obesity prevalence; (2) low physical activity levels based on deviations from national recommendations ${ }^{4}$; and (3) poor eating. Obesity prevalence was measured using the body mass index, with data from the 2011 Los Angeles County Healthy Survey for adults and the California Physical Fitness Testing Program [fitnessgram] for children. Low physical activity levels were measured using self-reports of "did not engage in vigorous activity 3 or more days" for 5- to 11-year-olds and "no moderate-tovigorous physical activity" for adults aged 18+ years; data source was the California Health Interview Survey. Finally, poor eating was measured via self-report of "excess junk food" consumption, using data from the 2011 Los Angeles County Health Survey. Excess junk food was defined in PRISM as food options that introduce excess calories without physiological benefits (eg, sugar-sweetened beverages, fried potato chips).

\section{Results}

\section{Policy, systems, and environmental context}

The policy/systems/environmental context scan systematically assessed CPPW strategies and field interventions that were disseminated across $88 \mathrm{mu}-$ nicipalities and 1 large unincorporated area in Los Angeles County. During 2010-2012, the $\$ 15.9$ million RENEW program focused on reducing obesity and related health conditions by employing a menu of healthy eating and active living strategy interventions. Collectively, this overall effort represented more than 40 interventions, addressing 8 key program objectives.

For healthy eating, RENEW strategies included the following: (1) adoption and implementation of nutrition standards and other healthy food procurement practices designed to improve access to healthy food environments within county and city governments and in the nation's second largest school district-Los Angeles Unified School District (>600 000 students); (2) adoption of breast-feeding practices, promoting supportive breast-feeding environments within hospitals and workplace settings; (3) corner store practices (eg, behavioral economics) and store infrastructure changes (eg, store makeovers) focused on increasing access to fresh produce in geographic areas with a low density of stores offering affordable fruit and vegetables; and (4) dissemination of multipronged health marketing cam- paigns focused on encouraging healthy eating behaviors. Table 1 provides examples of these strategies.

For active living, implemented strategies included such efforts as increasing staff capacity to help public school students meet physical education requirements, development and implementation of shared-use agreements to increase access to physical activity opportunities in areas with limited low-cost or free recreational opportunities, and a range of land use and transportation strategies that promoted walking and biking in the jurisdiction. Land use and transportation strategies included such efforts as (1) implementation of "complete streets" design practices that seek to ensure transportation improvements via future capital investments-in so doing, these designs would encourage walking, bicycling, and use of public transportation; (2) development of transit-oriented districts to foster pedestrian access to transit stations and encourage high-density, mixed-use development within a quarter mile of the transit stations-in so doing, these transit-oriented districts would help promote space and sustainable living arrangements; (3) completion of an environmental impact report for the County of Los Angeles ("County") bicycle master plan; (4) development of the County master plan for trails and bikeways that seeks to improve pedestrian and bike-friendliness in targeted communities; (5) development and implementation of a bicycle-friendly business district blueprint (eg, having community incentives for biking, improved space for biking) in the city of Long Beach; and (6) development of the South Bay bicycle master plan, which aimed to create bicycle-friendly environments and promote a bicycle culture in the region. Table 1 provides examples of these strategies.

\section{Forecasts of health impact}

On the basis of PRISM simulations, the highlighted program strategies, if sustained, have the collective potential by 2040 to reduce obesity in youth ( 29870 fewer cases) and adults (94136 fewer cases), the fraction of youth (112453 fewer cases) and adults (855855 fewer cases) who are below the recommended levels of physical activity, and the fraction of youth (14544 fewer cases) and adults (28835 fewer cases) who consume excess junk food or have a poor diet (Table 2).

\section{Discussion}

The diverse strategies implemented by RENEW in Los Angeles County varied in their reach, breadth, and depth. The policy/systems/environmental context scan provided a unique glimpse of the scope and landscape of the multisector, multilevel interventions. 


\section{TABLE 1 Communities Putting Prevention to Work Program-Healthy Eating and Active Living Policy/Systems/Environmental Change Strategies by Targeted Setting in Los Angeles County, 2010-2012}

Targeted Environment

Setting and Intervention

\section{Healthy Eating}

Institutional Food Service and Vending Venues

School Food Service and Vending Venues

Hospitals

Workplaces

At-risk/low socioeconomic status neighborhoods

Countywide
Setting: County of Los Angeles government ("County")

Intervention: Recommended and/or implemented healthy nutrition standards (ie, codified limits on calories and other nutrients such as sodium) and other healthy food procurement practices (eg, menu labeling, product placement) in food and vending services across the 37 departments in the County.

Setting: Select municipalities

Intervention: Recommended and/or implemented healthy nutrition standards (ie, codified limits on calories and other nutrients such as sodium) and other healthy food procurement practices (eg, menu labeling, product placement) in 10 low-income cities with high rates of obesity.

Setting: Select school districts

Intervention: Implemented Institute of Medicine school meal nutrition standards (ie, codified limits on calories and other nutrients such as sodium) and other healthy food procurement practices (eg, purchasing of locally grown foods, signage and product placement that promotes healthy food and beverage options, elimination of flavored milk) in at least 4 school districts, including the Los Angeles Unified School District (>600 000 students, affects $\sim 300000$ meals per day). Setting: Low-income preschools

Intervention: Promoted healthy nutrition policy guidelines and increased opportunities for physical education in at least 75 preschools located in low-income communities.

Setting: County of Los Angeles hospitals

Intervention: Achieved "baby-friendly" designation in 3 large, "safety-net" hospitals located across low-income areas to increase resources for and to promote breast-feeding among at-risk populations.

Setting: County of Los Angeles government

Intervention: Adopted lactation accommodation policies to create supportive workplace breast-feeding environments (eg, designate an appropriate private location for lactating women to express milk in the workplace, inform employees about the policy prior to maternity leave or upon returning to work) in 37 County departments.

Setting: Municipalities

Intervention: Adopted lactation accommodation policies focused on educating city of Los Angeles departments about federal and state laws related to breast-feeding to create safe spaces for employees who wish to continue nursing their children upon returning to work across city of Los Angeles departments.

Setting: Private employers

Intervention: Adopted lactation accommodation policies ranging from strengthening existing lactation accommodation policies to disseminating technical memos citing the US Department of Labor, Wage and Hour Division lactation policy to remind departments about state and federal lactation accommodation requirements to create supportive workplace breast-feeding environments across 2 private employers.

Setting: Select communities

Intervention: Implemented healthy corner store conversions (eg, increase access to fresh fruit and vegetables, improve product placement of healthy food and beverage options, decrease unhealthy food marketing) in 4 corner stores located across low-income neighborhoods identified as food deserts.

Setting: County of Los Angeles

Intervention: Disseminated the multipronged Choose Health LA initiative health marketing campaign focused on a variety of public health issues including high sugar-sweetened "sugary" beverage and sodium consumption among Los Angeles County residents through traditional media (eg, paid outdoor media campaign on transit and billboards [> 515 million impressions]) and multimedia approaches (eg, Twitter, Facebook, sendable e-cards, videos, online applications, Web site). 
TABLE 1 Communities Putting Prevention to Work Program-Healthy Eating and Active Living
Policy/Systems/Environmental Change Strategies by Targeted Setting in Los Angeles County, 2010-2012 (Continued)

Targeted Environment

Setting and Intervention

\title{
Active living
}

Schools

At-risk/low socioeconomic status communities

Countywide

\begin{abstract}
Setting: Select public schools
Intervention: Integrated staff development trainings and resources to support teacher capacity to implement existing, evidence-based physical education requirements at 50-70 public schools with high rates of childhood obesity.

Setting: Select school districts

Intervention: Implemented shared-use strategies establishing various partnerships (eg, schools, community organizations, County of Los Angeles departments) to increase public access to a variety of existing physical activity venues (ie, largely parks located on school facilities) in >10 schools across 5 school districts located in communities with few recreational venues to increase youth and adult opportunities for free or low-cost physical activity during nonschool hours.

Setting: County of Los Angeles

Intervention: Developed land use and/or transportation strategies (eg, bicycle master plans, transit-oriented districts, "complete streets" policies) to increase pedestrian activity and biking in the city of Los Angeles, 8 other cities, and the unincorporated areas of the county.
\end{abstract}

As the scan illustrated, the diversity of obesity prevention strategies implemented during CPPW (20102012) was immense. For example, for healthy eating objectives, the multipronged health marketing campaigns were developed to reach the entire Los Angeles County population, whereas the adoption of nutrition standards and other healthy food procurement practices was implemented only in selected institutional settings-yet, because they were implemented in school districts and cities, they had very broad population reach (>850000 students and adults). ${ }^{10,30,31}$ Other strategy interventions, such as the corner store conversions, targeted smaller geographic areas with low access to affordable, fresh produce and/or had among the highest burden of obesity. Similarly, active living strategies varied. Some land use and transportation strategies such as the update of the County bicycle master plan was meant to benefit all Los Angeles County residents, whereas shared-use agreements between schools and community partners were relatively small in scope but were highly portable and provided a potentially low-cost way to increase physical activity opportunities in low-income neighborhoods with limited open space. ${ }^{13,32}$ Collectively, these strategies, large and small, complemented each other to address the obesity burden distributed across Los Angeles County.

The simulated outcomes using PRISM suggest that CPPW investments should pay modest dividends over time, especially in terms of improved health behaviors in the next 2 decades. These more proximal outcomes, which are more valid in the short term, foreshadow fewer CVD events and mortality in the more distant future.
Although more research and program evaluation are clearly needed to confirm these estimates and demonstrate the actual effectiveness of these multisector strategies, the use of the context scan and PRISM to provide information about potential health impacts of local obesity prevention strategies has implications for local planning, program quality improvement efforts, and tailoring of future obesity prevention and control strategies to vulnerable populations.

\section{Limitations \\ Policy/systems/environmental context scan}

Although the breadth of the policy/systems/environmental context scan and its systematic approach represent strengths, there are a number of limitations to this analysis. First, the data gathered are generally qualitative and/or describe only program activities. They do not quantify intensity or dose-dependent effects of these activities. More analytic evaluations of the data were therefore not possible. Second, the data from the key informant interviews, while providing rich context and insights into program barriers and facilitators, offer no quantifiable indicators of progress or success. Finally, reviews of program data often require some degree of judgment by evaluators on the relevance of the information being reviewed. In these instances, bias can be introduced and not easily accounted for in the context scan.

\section{PRISM}

PRISM is a population model and although the model calculates age and gender strata separately, available 


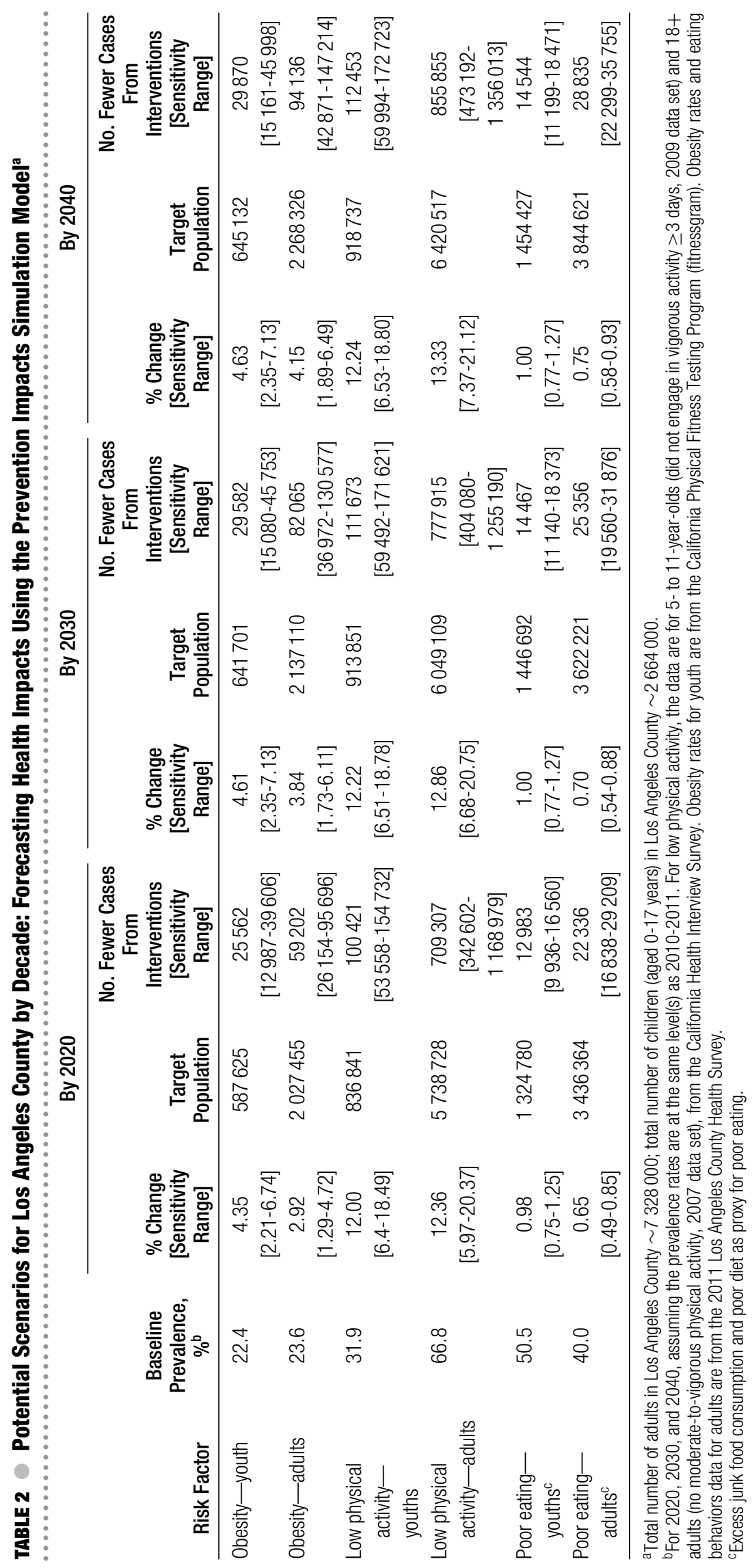


results are generally population averages. Thus, the model does not typically allow simulations of health impacts of targeted strategies either for specific age groups or for geographic areas smaller than that of the regional/county level. In Los Angeles County, for example, this yielded model estimates that were highly relevant for planning at the county level but lacked specificity for use at the city or community level where the obesity burden may be variable or comparatively different..$^{33}$ Although PRISM includes most of the known CVD risk factors, many have been omitted. In addition, other risk factors affecting non-CVD chronic diseases were excluded during the model construction.

\section{Conclusions}

Program context and PRISM simulations of CPPW strategies in Los Angeles County showed promising results, which may lead to overall population health improvements in the future. However, analysis of future health and behavioral surveillance data as well as better characterization of cost-benefits of these multisector, multilevel strategy interventions will be needed to confirm these forecasts and help inform future efforts seeking to improve these and other obesity prevention strategies implemented in the region.

\section{REFERENCES}

1. Story M, Kaphingst KM, Robinson-O'Brien R, Glanz K. Creating healthy food and eating environments: policy and environmental approaches. Ann Rev Public Health. 2008;29:253272.

2. Wang Y, Beydoun MA. The obesity epidemic in the United States-gender, age, socioeconomic, racial/ethnic, and geographic characteristics: a systematic review and metaregression analysis. Epidemiol Rev. 2007;7(29):6-28.

3. Bunnell R, O'Neil D, Soler R, et al. Communities Putting Prevention to Work Program Group. Fifty communities putting prevention to work: accelerating chronic disease prevention through policy, systems, and environmental change. J Community Health. 2012;37(5):1081-1090.

4. National Prevention Council. National Prevention Strategy. Washington, DC: US Department of Health and Human Services, Office of the Surgeon General; 2011.

5. Institute of Medicine of the National Academies. School Meals: Building Blocks for Healthy Children. Washington, DC: National Academies Press; 2009. http://www.iom.edu/Reports/ 2009/School-Meals-Building-Blocks-for-Healthy-Children. aspx. Accessed November 13, 2012.

6. Lovasi GS, Hutson MA, Guerra M, Neckerman KM. Built environments and obesity in disadvantaged populations. Epidemiol Rev. 2009;31:7-20.

7. Khavjou OA, Honeycutt AA, Hoerger TJ, Trogdon JG, Cash AJ. Collecting costs of community prevention programs: communities putting prevention to work initiative. Am J Prev Med. 2014;47(2):160-165
8. Sturm R, Hattori A. Diet and obesity in Los Angeles County 2007-2012: is there a measurable effect of the 2008 "Fast-Food Ban"? Soc Sci Med. 2015;133:205-211.

9. Shih M, Du Y, Lightstone AS, Simon PA, Wang MC. Stemming the tide: rising diabetes prevalence and ethnic subgroup variation among Asians in Los Angeles County. Prev Med. 2014;63:90-95.

10. Robles B, Wood M, Kimmons J, Kuo T. Comparison of nutrition standards and other recommended procurement practices for improving institutional food offerings in Los Angeles County, 2010-2012. Adv Nutr. 2013;4:191-202.

11. Cummings PL, Welch SB, Mason M, Burbage L, Kwon S, Kuo T. Nutrient content of school meals before and after implementation of nutrition recommendations in five school districts across two U.S. counties. Prev Med. 2014;67(suppl 1):S21-S27.

12. Cummings PL, Burbage L, Wood M, Butler RK, Kuo T. Evaluating changes to sodium content in school meals at a large, urban school district in Los Angeles County, California. J Public Health Manag Pract. 2014;20(1)(suppl 1): S43-S49.

13. Lafleur M, Gonzalez E, Schwarte L, et al. Increasing physical activity in under-resourced communities through schoolbased, joint-use agreements, Los Angeles County, 2010-2012. Prev Chronic Dis. 2013;10:E89.

14. Lafleur M, Cole BL, Banthia R, Sivasubramanian R, Garcia R. Physical education and student activity: Evaluating implementation of a new policy in Los Angeles public schools. Ann Behav Med. 2013;45(suppl 1):S122-S130.

15. Oka M, Link CL, Kawachi I. Area-based variations in obesity are more than a function of the food and physical activity environment. J Urban Health. 2013;90(3):442-463.

16. Barragan NC, Robles B, Gase LN, et al. The "Sugar Pack" health marketing campaign in Los Angeles County, 20112012. Health Promot Pract. 2013;15(2):208-216.

17. Research \& Evaluation, Division of Chronic Disease and Injury Prevention, Los Angeles County Department of Public Health. Consumption of Sugar-Sweetened Beverages in Los Angeles County. Los Angeles, CA: Los Angeles County Department of Public Health; 2011.

18. Frieden TR. A framework for public health action: the health impact pyramid. Am J Public Health. 2010;100(4):590-595.

19. Homer J, Wile K, Yarnoff B, et al. Using simulation to compare established and emerging interventions to reduce cardiovascular disease risk in the United States. Prev Chronic Dis. 2014;11:140130.

20. American Recovery and Reinvestment Act. Prevention and Wellness Initiative: Communities Putting Prevention to Work. http://www.cdc.gov/chronicdisease/recovery/PDF/ HHS_CPPW_CommunityFactSheet.pdf. Published March 2010. Accessed April 26, 2012.

21. Los Angeles County Department of Public Health. Los Angeles County Health Survey, 2011. Public Health Department Web site. http:publichealth.lacounty.gov/ha/hasurveyintro. htm. Accessed April 25, 2013.

22. Los Angeles County Department of Public Health. County of Los Angeles Department of Public Health: Strategic Plan 2008-2011. Public Health Department Web site. http:/ / public health.lacounty.gov/plan/docs/S-plan5.pdf. Published August 2008. Accessed April 20, 2013. 
23. Homer J, Milstein B, Wile K, Pratibhu P, Farris R, Orenstein D. Modeling the local dynamics of cardiovascular health: risk factors, context, and capacity. Prev Chronic Dis. 2008;5(2). http: //www.cdc.gov/pcd/issues/2008/apr/07_0230.htm. Published April 2008. Accessed April 29, 2013.

24. Hirsch G, Homer J, Wile K, Trogdon JG, Orenstein D. Using simulation to compare 4 categories of intervention for reducing cardiovascular disease risks. Am J Public Health. 2014;107(7):1187-1195.

25. Green LW, Kreuter MW. A framework for planning. In:Barrett N, O'Brien G, eds. Health Program Planning: An Educational and Ecological Approach. New York, NY: McGrawHill; 2004:1-28.

26. Harris JE, Gleason PM, Sheean PM, Boushey C, Beto JA, Bruemmer B. An introduction to qualitative research for food and nutrition professionals. J Am Diet Assoc. 2009;109:80-90.

27. Homer J, Milstein B, Wile K, et al. Simulating and evaluating local interventions to improve cardiovascular health. Prev Chronic Dis. 2010;7(1):A18. http://www.cdc.gov/pcd/ issues/2010/jan/08_0231.htm. Accessed April 29, 2013.

28. Loyo HK, Batcher C, Wile K, Huang P, Orenstein D, Milstein B. From model to action: using a system dynamics model of chronic disease risks to align community action. Health Promot Pract. 2013;14(1):53-61.

29. The PRISM External Review Panel. Previewing PRISM. Observations and Suggestions from the Prevention Impacts Simulation Model (PRISM) External Review Panel. Fairfax, VA: ICF International; 2012.

30. Briefell RR, Crepinsek MK, Cabili C, Wilson A, Gleason PM. School food environments and practices affect dietary behaviors of US public school children. J Am Diet Assoc. 2009;109(suppl 2):S91-S107.

31. Food and Nutrition Service, US Department of Agriculture. Nutrition standards in the National School Lunch and School Breakfast Programs. Final rule. Fed Regist. 2012;77(17):40885167.

32. Wechsler H, Devereaux RS, Davis M, Collins JL. Using the school environment to promote physical activity and healthy eating. Prev Med. 2000;31:S121-S137.

33. Office of Health Assessment and Epidemiology. Obesity and related mortality in Los Angeles County: a cities and community health report. http://publichealth.lacounty.gov/ha/ reports/habriefs/2007/Obese_Cities/Obesity_2011Fs.pdf. Published September 2011. Accessed April 30, 2013. 